\title{
Dissecting Aortic Aneurysm 55 Years after Diagnosis of Iris Flocculi
}

\author{
Jerry A. Shields ${ }^{a}$ George N. Magrath $^{\mathrm{a}}$ Carol Shields $^{\mathrm{a}}$ Richard Mackool $^{\mathrm{d}, \mathrm{e}}$ \\ Ralph C. Eagle Jr. ${ }^{b}$ Hans E. Grossniklaus ${ }^{c}$ \\ a Ocular Oncology Service and b Pathology Department, Wills Eye Hospital, Thomas Jefferson University, \\ Philadelphia, Pa., 'Department of Ophthalmic Pathology, Emory University, Atlanta, Ga., ${ }^{\mathrm{d}}$ Mount Sinai New York

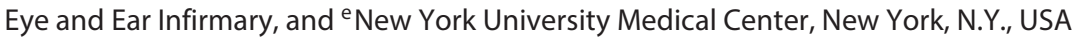

\section{Key Words}

Eye $\cdot$ Iris $\cdot$ Iris pigment epithelium $\cdot$ Iris flocculi · Cysts .

Tumor $\cdot$ Aorta $\cdot$ Dissecting aneurysm

\begin{abstract}
Purpose: The aim of this study is to report the clinical features, imaging studies, surgical removal, and pathology of congenital iris flocculi in a patient who developed a lifethreatening dissecting aortic aneurysm after 55 years of follow-up. Methods: Documentation with iris photography was performed from age 18 to 55 years, at which time anterior segment optical coherence tomography (OCT) was performed. At the time of subsequent cataract surgery, the iris flocculi were removed in each eye and submitted for light and electron microscopy. Results: The size and shape of the iris flocculi waxed and waned over the years but caused no visual disturbance. Anterior segment OCT demonstrated clear, round cysts with thin lining and no solid component. At the age of 55, congestive heart failure from a dissecting aortic aneurysm was discovered and surgically repaired. Subsequent bilateral cataract surgery and cyst removal were performed, and the iris flocculi were studied with light
\end{abstract}

and electron microscopy. Conclusions: Congenital iris flocculi cause little, if any, visual impairment in most cases. However, they are occasionally associated with dissecting aortic aneurysm due to a shared mutation in smooth muscle that affects both the iris and the aorta. Patients with iris flocculi should be monitored periodically for aortic abnormalities.

(c) 2016 S. Karger AG, Basel

\section{Introduction}

The iris pigment epithelium (IPE) can give rise to cysts in the pupillary margin, midzonal region, or iridociliary sulcus [1-3]. Multiple congenital bilateral pupillary margin IPE cysts (also termed iris flocculi) are often readily visible as spherical or tear-drop-shaped pigmented lesions. They appear at a young age, can overhang the pupil but only occasionally cause visual symptoms [1-3]. In some patients with iris flocculi, there is a mutation of smooth muscle alpha-actin 2 (ACTA2) and/or mutation in the smooth muscle gene (MYH11) that also affects the similar smooth muscles in the aorta, sometimes leading

\section{KARGER}

E-Mail karger@karger.com

www.karger.com/oop
(C) 2016 S. Karger AG, Base

2296-4681/16/0024-0222\$39.50/0
Jerry A. Shields, MD

Ocular Oncology Service, Suite 1440, Wills Eye Hospital 840 Walnut Street

Philadelphia, PA 19107 (USA)

E-Mail jerryashields@ gmail.com 

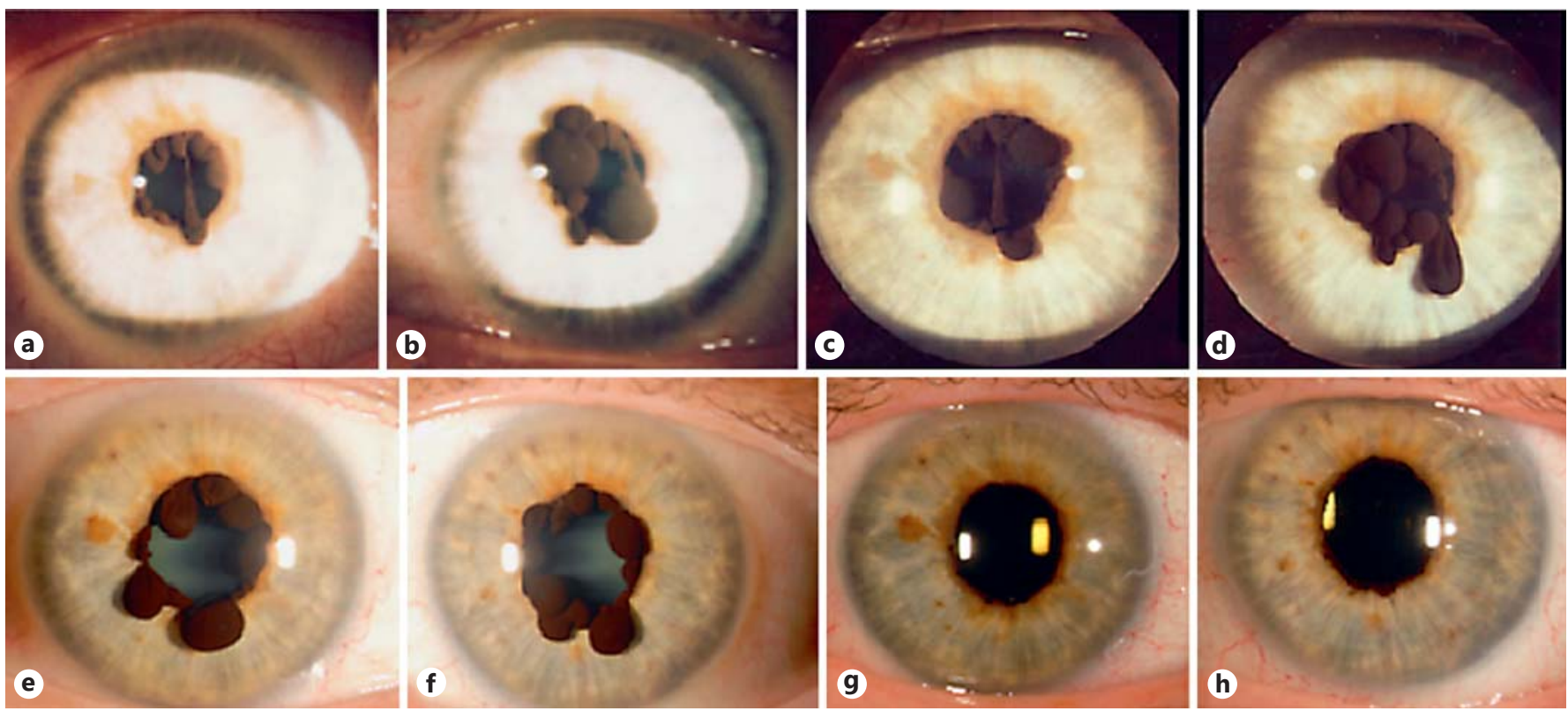

Fig. 1. IPE cysts of the pupillary margin (iris flocculi) followed over several years. a, b Appearance in 1985. c, d Appearance in 1990. e, f Appearance in 2014. Note that over those years, the cysts showed changes in morphology, but the patient had no visual complaints. g, h Appearance in 2015 after bilateral cataract surgery and cyst removal.

Fig. 2. Anterior segment OCT of IPE cysts before and after cyst removal. a, b Appearance in 2014, showing the thin-walled cysts anterior to the pupillary border at low power in the right (a) and left (b) eyes and at high power in the right (c) and left (d) eyes. Following cataract surgery and IPE cyst resection, the iris configuration appears normal in the right (e) and left (f) eyes.
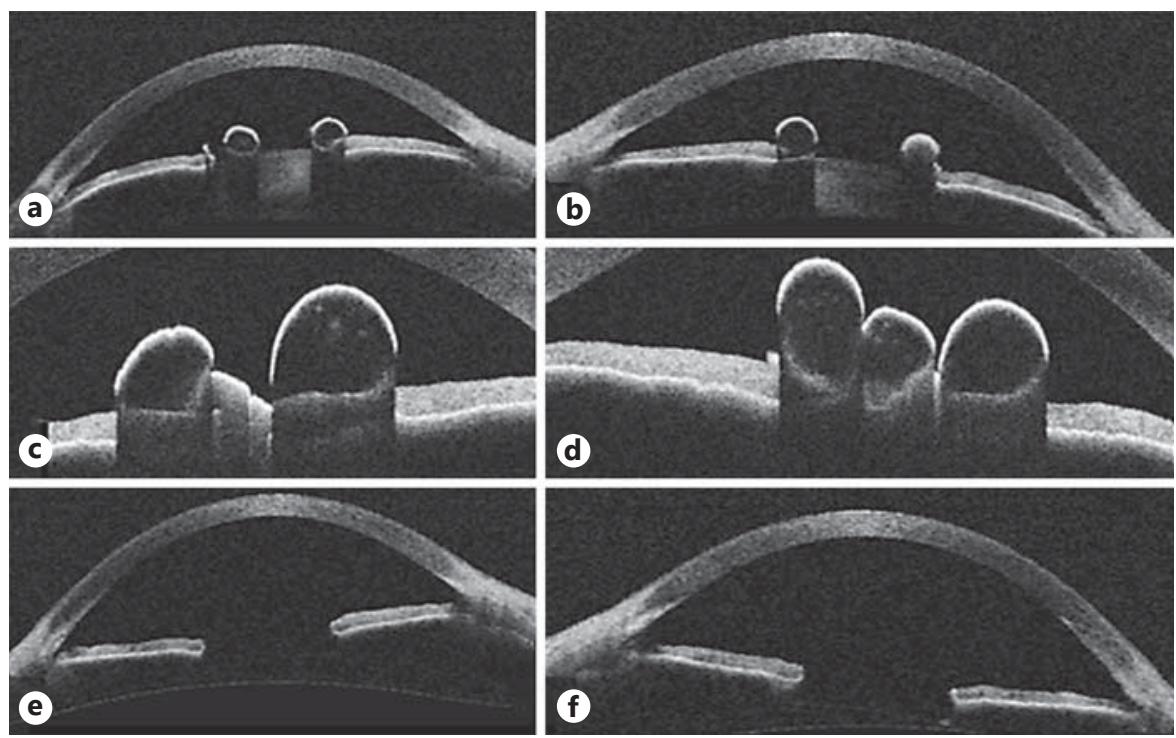

to thoracic artery aneurysm and dissection (TAAD) [413]. We report a patient with iris flocculi that were detected in childhood and followed for many years. When he was 55 years old, he developed a life-threatening dissecting aortic aneurysm that was successfully repaired. We discuss the clinical features, genetics, and histopathology and electron microscopy of iris flocculi in this patient.

Aneurysm with Iris Flocculi

\section{Case Report}

An 18-year-old asymptomatic male was referred to the Oncology Service in 1978 for bilateral iris lesions. His parents recalled first noticing the asymptomatic lesions shortly after birth. Medical and family histories were unremarkable. On examination, there were multiple dark-brown cystic iris lesions at the pupillary border in each eye, typical of iris flocculi. In 1985 (fig. 1a, b) and 1990 (fig. 1c, d), the cysts were photographically documented, with

Ocul Oncol Pathol 2016;2:222-225 
slight change and occasional collapse and reformation. The patient subsequently had 3 healthy children who demonstrated no ocular abnormalities.

The patient was followed elsewhere for 24 years. In July 2014, when he was 55 years old, he returned with visual impairment to $20 / 60$ in each eye due to bilateral cataracts. The iris flocculi had changed slightly in appearance but were still asymptomatic (fig. 1e, f). Optical coherence tomography (OCT) demonstrated multiple clear cysts at the pupillary border in each eye (fig. $2 a-d)$. At that

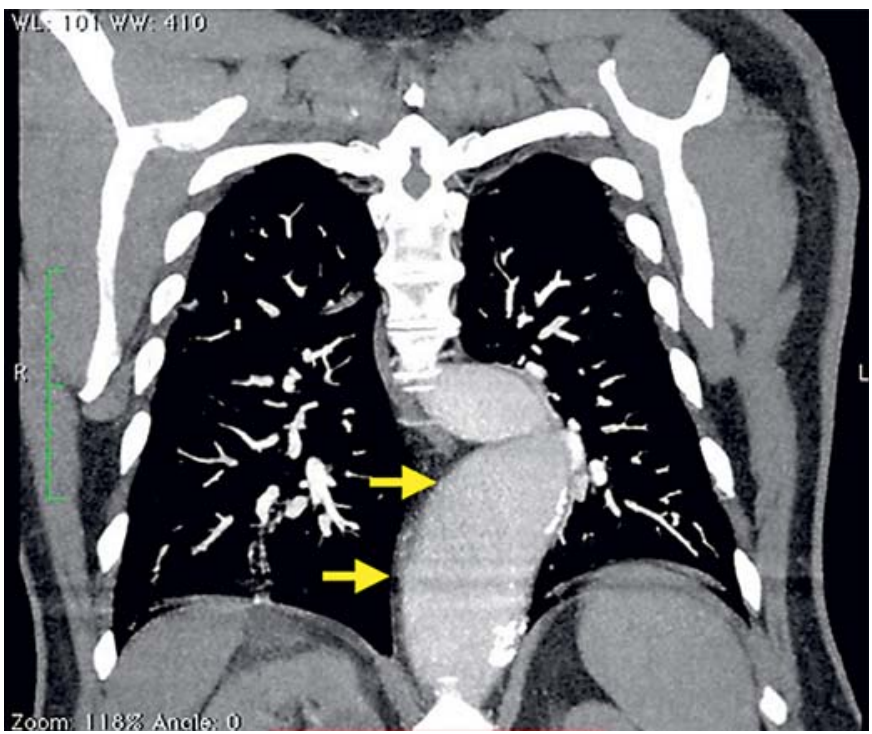

Fig. 3. Computed tomography of the chest, showing the dissecting aortic aneurysm (yellow arrows). time, he reported having developed systemic hypertension and congestive heart failure 4 months earlier and was found to have TAAD (fig. 3) on computed tomography, necessitating surgical repair.

The patient underwent genetic studies to detect mutations of smooth muscle focusing on disorders known to cause TAAD, including ACTA2, MYH11, and 14 others, but no disease-causing mutations were detected. Exon analysis for duplications or deletions in known familial TAAD genes was negative (GeneDx TAAD panel). According to the laboratory report, this panel is known to detect a disease-causing mutation in $20 \%$ of the familial TAAD patients. Light microscopy of the iris flocculi showed mostly normal IPE cells. Electron microscopy revealed a disorderly membrane of iris pigment epithelial cells and scant smooth muscle containing deposits of extracellular matrix material (fig. 4).

Subsequent bilateral cataract surgery with cyst removal was performed (R.M.), and visual acuity returned to 20/20 in each eye (fig. 1g, h; online suppl. digital content video 1; for all online suppl. material, see www.karger.com/doi/10.1159/000445719).

\section{Discussion}

The patient reported here demonstrated relatively stable iris flocculi from birth through the adult years and then developed a related life-threatening TAAD at the age of 55. Iris flocculi are benign cystic lesions that rarely lead to serious visual problems [1-3]. However, the presence of iris flocculi should alert the clinician to monitor the patient for TAAD as there is occasionally a genetic relationship of iris flocculi with this life-threatening cardio-

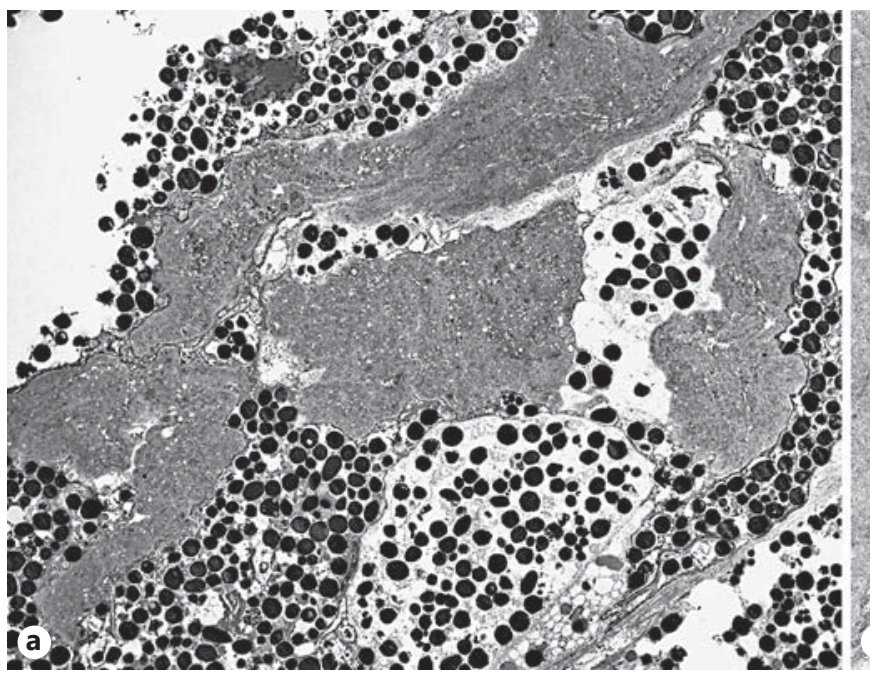

Fig. 4. a Transmission electron microscopy, revealing the disorderly aggregate of IPE cells with large melanin granules separated by osmophilic deposits of extracellular matrix material. b Higher magnification of extracellular matrix material, showing multiple

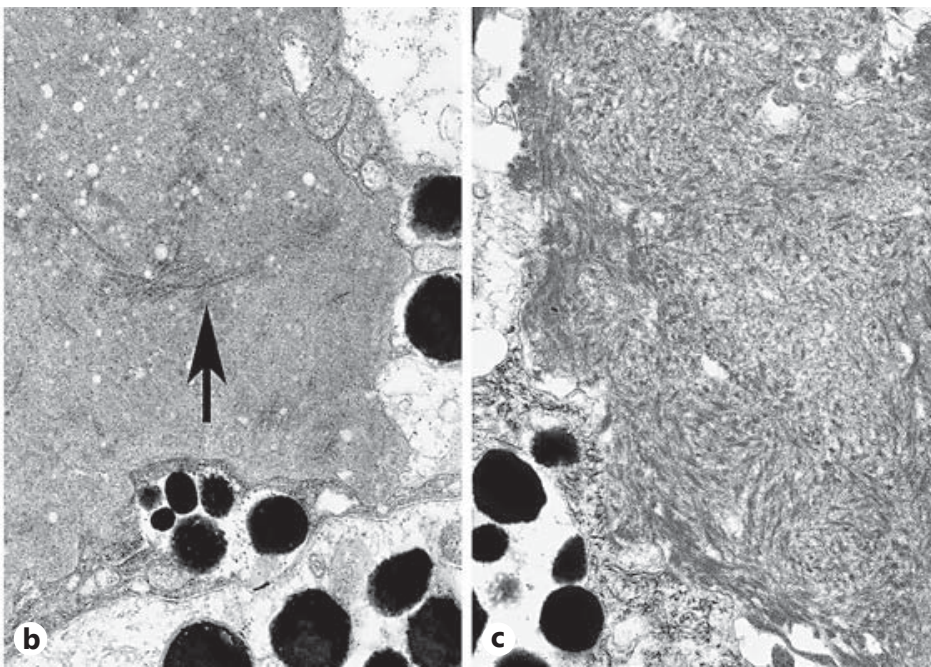

small vacuoles and collagen fibers (arrow; original magnification $\times 7,200)$. c Focus of presumed degenerated smooth muscle contains fibrillar material thought to represent actin filaments (original magnification $\times 10,000)$.
Ocul Oncol Pathol 2016;2:222-225

DOI: $10.1159 / 000445719$
Shields/Magrath/Shields/Mackool/ Eagle Jr./Grossniklaus 
vascular disease of adulthood. This relationship is linked by genetic mutation affecting smooth muscle cells in both the aorta and the iris. Mutation in ACTA2 [7] and MYH11 have been identified in patients with TAAD and iris flocculi. The ACTA2 gene plays a role in actin filament assembly and smooth muscle contraction, which is important in contracting both the iris sphincter muscle and the aorta [7]. However, in this patient, the genetic testing was unrevealing. This suggests that other unknown genes may underlie this condition, or the relationship may be coincidental. Clinically, however, most patients with TAAD do not have demonstrable iris flocculi. Disabella et al. [8] reviewed 100 patients with TAAD and found only 6 patients with iris flocculi.

Histopathology of TAAD demonstrates loss of smooth muscle cells in the medial layer of the aortic wall, a feature thought to lead to the development and dissection of aneurysms [7]. Similar findings are believed to occur in iris flocculi. Light microscopy of the iris flocculi in our case revealed IPE but very little smooth muscle, perhaps because of the scant material in the specimen. Our patient underwent extensive genetic studies by a reliable laboratory, and no mutations were found in smooth muscle genes. No explanation for this finding was rendered.

Concerning the management of iris flocculi, most patients are visually asymptomatic and require no treatment [1-3]. Paradoxically, if the cysts encroach on the pupil, they can produce a pinhole effect that can improve visual acuity. For symptomatic patients, laser photocoagulation with cyst rupture or surgical removal of cysts can be employed. In our patient, cyst removal was performed at the time of cataract surgery with an excellent outcome.

In summary, we report long-term follow-up of iris flocculi in a patient who eventually developed TAAD, a serious cardiovascular disease that can be fatal. We emphasize the importance of recognizing this benign congenital ocular condition because of its potential relationship to TAAD. Patients and related family members with iris flocculi should be examined and monitored for this catastrophic cardiovascular condition.

\section{Acknowledgements}

Support was provided by the Eye Tumor Research Foundation, Philadelphia, Pa. (J.A.S., C.S.), the Paul Kayser International Award of Merit in Retina Research, Houston, Tex. (J.A.S.), Lift for a Cure, Morrisdale, Pa. (C.S., J.A.S.), and the Lucille Wiedman Fund for Pediatric Eye Cancer, Philadelphia, Pa. (C.S., J.A.S.).

\section{Statement of Ethics}

The patient gave informed consent. However, Institutional Review Board approval was not required per Wills Eye Hospital's case study guidelines.

\section{Disclosure Statement}

No conflicting relationship exists for any author.

\section{References}

1 Shields JA, Shields CL: Iris cysts; in Shields JA, Shields CL: Intraocular Tumors. An Atlas and Textbook, ed 3. Philadelphia, Wolters Kluwer, 2016, pp 51-59.

2 Shields JA: Primary cysts of the iris. Trans Am Ophthalmol Soc 1981;79:771-809.

3 Lois N, Shields CL, Shields JA, Mercado G: Primary cysts of the iris pigment epithelium: clinical features and natural course in $234 \mathrm{pa}-$ tients. Ophthalmology 1998;105:1879-1885.

4 Bixler D, Antley RM: Familial aortic dissection with iris anomalies - a new connective tissue disease syndrome? Birth defects Orig Artic Ser 1976;12:229-234.

5 Lewis RA, Merin LM. Iris flocculi and familial aortic dissection. Arch Ophthalmol 1995;113: 1330-1331.
6 Phowthongkum P, Burapasubkajorn P, Intarabeth $\mathrm{P}$, et al: Familial aortic dissection and congenital iris flocculi with hypertension. Ophthalmic Genet 2008;29:126-127.

7 Hashida N, Ohguro N, Morimoto Y, et al: Ultrastructural appearance of iris flocculi associated with a thoracic aortic aneurysm and dissections. Br J Ophthalmol 2009;93:14091410.

8 Disabella E, Grasso M, Gambarin FI, et al: Risk of dissection in thoracic aneurysms associated with mutations of smooth muscle alpha-actin 2 (ACTA2). Heart 2011;97:321326.

9 Risma TB, Alward WL: Successful long-term management of iris flocculi and meiosis in a patient with a strong family history of thorac- ic aortic aneurysms and dissections associated with an MYH11 mutation. JAMA Ophthalmol 2014; 132:778-780.

10 Weissman HM, Wells JR: Iris flocculi. JAMA Ophthalmol 2014;8:132-135.

11 Sallo FB, Hatvani I: Recurring transitory blindness caused by primary marginal pigment epithelial cysts. Am J Ophthalmol 2002; 133:407-409.

12 Sallo FB, Hatvani I: Surgical treatment of symptomatic primary pupillary pigment epithelial iris cysts. Acta Ophthalmol Scand 2003;81:191-192.

13 Guo D-C, Pannu H, Tran-Fadulu V, et al: $\mathrm{Mu}$ tations in smooth muscle alpha-actin (ACTA2) lead to thoracic aortic aneurysms and dissections. Nature Genet 2007;39:1488-1493. 